\title{
EL TANGO ARGENTINO EN RECEPCIÓN: INTERPRETACIÓN Y APROPIACIÓN DE UNA LÍRICA QUE INVOLUCRA MADRES SANTAS, CONSEJOS CÍNICOS Y VIOLENCIA DE GÉNERO
}

\section{ARGENTINE TANGO IN RECEPTION: INTERPRETATION AND APPROPRIATION OF LYRICS INVOLVING HOLY MOTHERS, CYNICAL ADVICE, AND GENDER VIOLENCE}

\author{
María de los Ángeles MONTES \\ Consejo Nacional de Investigaciones Científicas y Técnicas (Argentina) \\ montes.m.angeles@gmail.com
}

Resumen: La madre santa, los consejos cínicos, o las historias de amor atravesadas por situaciones de violencia de género son lugares comunes de una parte importante de la lírica del tango argentino. Se trata de historias y personajes que van a contrapelo de lo decible de nuestro tiempo. Por este motivo nos propusimos indagar en las operaciones interpretativas y las prácticas de apropiación que les permiten a los tangueros de la ciudad de Córdoba (R. Argentina), disfrutar de esos tangos plagados de personajes y acciones que serían reprochables desde sus propios sistemas de valores.

Palabras clave: Operaciones interpretativas. Prácticas de apropiación. Recepción. Elementos disonantes. Tango.

Abstract: The veneration of the mother figure, the "Holy Mother", cynical advice, or love stories surrounded by situations of domestic violence are commonplace and an important part of the Argentine tango lyric. These are stories and characters that run counter to the social and moral standards of our time. For this reason, we set out to investigate the interpretative operations and ownership practices that allow the dancers of the city of Cordoba (Republic of Argentina), to enjoy those tangos riddled with characters and actions that would be reprehensible from their very own value systems.

Key Words: Interpretative Operations. Practices of Appropriation. Reception. Dissonant elements. Tango. 


\section{INTRODUCCIÓN}

\subsection{CUESTIÓN DE INTERPRETACIÓN Y APROPIACIÓN: UN PROBLEMA SOCIOSEMIÓTICO}

La lírica' del tango argentino recoge en sus cientos de letras los personajes, las historias y los sentires de varias generaciones de argentinos que, durante la primera mitad del siglo $\mathrm{XX}$, dieron forma al tango según sus creencias y moralidades. Algunos tópicos son característicos de esa lírica popular y en gran medida lo definen como género: la madre, la milonguita, el barrio, la nostalgia, el escepticismo, la fractura amorosa, etc. (Archetti, 2003; Ulla, 1982; Moreau, 2000).

En esa lírica materializada en canciones, se describen personajes y se narran historias que a veces tienen poco en común con los valores y creencias de sus consumidores actuales en la ciudad de Córdoba, los cuales pertenecen principalmente a los estratos sociales medios ${ }^{2}$. Es precisamente por la comprobación de esta distancia en lo que respecta a las creencias y valores que asumen sus actuales consumidores y esta lírica, que surgen interrogantes sobre los procesos a través de los cuales estos discursos adquieren sentido para ellos en la instancia de la recepción. En este trabajo pretendemos comunicar resultados parciales de una investigación de corte sociosemiótico, realizada en el ambiente milonguero de la ciudad de Córdoba, sobre la recepción que realizan estos consumidores del tango ${ }^{3}$.

Hablar de recepción como instancia donde se produce sentido nos coloca, en términos semióticos, del lado de las teorías interpretativistas (Paolucci, 2013) fundadas sobre la base del paradigma peirceano. Desde este paradigma, el sentido viene siempre realizado en la recepción a través de procesos inferenciales que involucran creencias y reglas interpretativas socialmente producidas y compartidas (hábitos). Habilita, así, la posibilidad de pensar los corrimientos de sentido, las mutaciones y los cambios, pero manteniendo a la comunidad como garante intersubjetivo de la semiosis (Eco, 1992:

1 En este trabajo se entiende por la lírica al conjunto de las obras líricas de un determinado autor, época o género, que tienen por objeto comunicar sentimientos o emociones, y que presentan características comunes de motivo y estilo.

2 Esta es una tendencia evidente en la ciudad de Córdoba (segunda ciudad más importante de Argentina), según nosotros pudimos constatar durante el trabajo de campo, pero también en otras ciudades argentinas como, por ejemplo, la propia ciudad de Buenos Aires (Liska, 2012).

3 Milongueros es como se autodefinen quienes asisten regularmente a las milongas, salones de baile donde se escucha y se baila el tango de salón. Estas personas, además de bailar el tango con fines sociales, eligen el tango como su música preferida también en la escucha privada. El tango no es, para ellos, un consumo cultural más. A través de ese consumo y de su filiación al género musical se autodefinen y se distinguen de otros grupos sociales. 
369). Ahora bien, esa semiótica ha sido fundamental para comprender los procesos interpretativos pero no se ha ocupado del estudio de las prácticas de apropiación, un problema que sí fuera tratado desde la sociología posestructuralista (De Certeau, 2000). Claro está, entre una tradición y otra hay abismos semióticos y epistemológicos difíciles de ignorar. De Certeau, por ejemplo, y toda la sociología derivada de su trabajo, asumen la productividad de las "artes de hacer" pero en ningún momento cuestionan la biplanaridad del signo saussureano ni la (pre)determinación del significado por las relaciones que establecen dentro (y solo dentro) del propio sistema (Montes, 2015a).

Es por este motivo que aquí partimos del marco general que brindan la semiótica y la epistemología pragmatista, para introducir la cuestión de las apropiaciones de los signos en el sentido más literal del término como "hacer propio". Nuestra empresa se sitúa precisamente en la intersección entre estas problemáticas de índole semiótico y sociológico, pero desde la mirada pragmática. Desde este marco general denominamos operaciones interpretativas a aquellas operaciones cognitivas que derivan en el establecimiento de un signo interpretante que permite el reconocimiento del objeto por el que se encuentra el signo/discurso, incluyendo su ineludible valoración. Reconocimiento y valoración conforman lo que denominamos interpretación, mientras que reservamos el término apropiación para lo que los sujetos hacen con esos signos interpretantes en un paso lógicamente posterior. Las apropiaciones, por su parte, se distinguen de las interpretaciones por su lugar lógico en el proceso, pero también por el lugar especial que ocupa en ellas el sujeto. Lo que caracteriza a las interpretaciones en comparación con las apropiaciones es que el sujeto las percibe como motivadas por el signo, de alguna manera obligadas, mientras a las apropiaciones las percibe, generalmente, como más dependientes de su opinión, de su voluntad o de sus necesidades. Lo cual no quiere decir que no estén fuertemente reglamentadas. Por el contrario, lo que se puede o no hacer con una canción, por ejemplo, está también regulado socialmente. Pensemos, por ejemplo, en el caso del Himno Nacional Argentino versionado por el rockero Charly García en 1990 que, en su momento, le costó una denuncia judicial por supuesta ofensa a los símbolos patrios4. Lo que pretendemos decir, en cambio, es que las reglas que establecen las apropiaciones legítimas en una comunidad determinada van mucho más allá del simple reconocimiento y habilitan la acción de los sujetos con los signos. Estos usos, como los llamaba Eco (1992), no por ser distintos y lógicamente posteriores a la interpretación

4 Actualmente la canción ha sido versionada por múltiples rockeros y su adaptación al género ya no causa este tipo de reacciones, lo cual demuestra no sólo que las apropiaciones están socialmente reguladas, sino que esas regulaciones se modifican con el paso del tiempo y, lo que es más importante, con la práxis de los agentes sociales. El escándalo protagonizado por García, en su momento, desató un intenso debate en el país acerca del valor de tales símbolos y sobre lo es que correcto o no hacer con ellos y, ulteriormente, llevó al relajamiento de las restricciones sociales sobre su apropiación. 
carecen de interés sociosemiótico. Las prácticas de apropiación también son productoras de sentido y, además, permiten en muchos casos comprender la vigencia de, en nuestro caso, una lírica que lleva un siglo de vida y que emerge de condiciones sociales muy distintas a las de sus actuales consumidores (como pretendemos desarrollar en esta comunicación).

En este marco nos preguntamos: ¿Qué operaciones interpretativas y qué prácticas de apropiación ponen en marcha los milongueros cordobeses para dar sentido al tango y hacer que mantenga vigencia? Y, más específicamente, ¿qué ocurre con esos tangos cuyas letras son potencialmente disonantes con la moral de clase media de estos consumidores del tango?

\subsection{ANTECEDENTES Y METODOLOGÍA EMPLEADA}

Para responder a estas preguntas, entre otras, realizamos una investigación dentro del circuito milonguero de la ciudad de Córdoba. Se llevó adelante un trabajo de campo durante 4 años que incluyó la observación participante y varias tandas de entrevistas con un gradual incremento de la direccionalidad. Se concluyó con una variante de entrevista focalizada (Merton, Fiske $\&$ Kendall, 1998) denominada entrevista productiva (Montes, 2015b), donde los informantes debieron realizar actividades de traducción inter e intra semióticas de un corpus de tangos previamente seleccionados en función de su potencial para despejar hipótesis. Estas actividades consistían, en algunos casos, en la topicalización de esas letras de tangos -determinar cuál era, a criterio de los entrevistados, el tema central de la letra- $y$, en otros, de la traducción de esos versos a narraciones. Luego se les solicitaba que dieran su opinión sobre esas letras, que dijeran si eran de su agrado o no, y las razones de esas valoraciones.

Para la selección de los entrevistados se realizó un muestreo teórico (Glasser \& Strauss, 1967) que privilegió los casos típicos (Patton en Flick, 2001:82), de milongueros con más de dos años de permanencia en el campo -para asegurarnos su compromiso identitario-, con edades de entre 22 y 65 años, y uniformemente distribuidos entre varones y mujeres.

Allí pudimos observar que, en el caso de las letras, ellos operan sobre el universo discursivo del tango topicalizando primero, y seleccionando -apropiándose- luego unos tópicos por sobre otros para construir a través de estas selecciones sus propias narrativas identitarias ${ }^{5}$ (Montes, 2016b). Así el tópico romántico amoroso aparecía entre sus selecciones preferenciales, mientras que otros como la madre, el juego o la

5 Sobre la adaptación de la noción de narrativas identitarias, de Paul Ricoeur, para la comprensión de la apropiación de las músicas populares véase el trabajo de Pablo Vila (1996). 
vida nocturna no emergían entre sus prioridades ${ }^{6}$. En todos los casos las selecciones de los entrevistados en materia de letras evitó sistemáticamente aquellas con elementos potencialmente conflictivos con la moral de clase media cordobesa. En estas canciones que hablan del amor no había referencias a la prostitución, a la delincuencia o a la violencia física; elementos presentes en una parte importante del universo lírico del tango argentino. Los tangos prostibularios, los que coinciden con la matriz moral del machismo bárbaro (Saikin, 2004), eran sistemáticamente evitados por los entrevistados en sus opciones primeras ${ }^{7}$.

La selección que realizaban resultaba coherente en el marco del uso que ellos hacían de esa lírica, del modo como se la apropiaban. Esta poesía amorosa, lavada de violencia y de comercio sexual, les servía para hablar de sí mismos: identificándose con el enunciador conseguían que esa lírica evocara sus propias expectativas amorosas, sus propias experiencias o, incluso, sus propias ilusiones (Montes, 2016a).

Pero, ante esto, emergió la incógnita sobre cómo interpretaban ellos esas otras canciones que también forman parte del universo discursivo del tango y que eran frecuentemente escuchados en las milongas cordobesas. Saber que esos tangos potencialmente disonantes no forman parte de sus selecciones primeras no nos decía nada sobre si eran rechazados (total o parcialmente). No nos decía nada, ni siquiera, sobre si esa disonancia efectivamente se producía.

Para abordar esta cuestión se incluyó en las entrevistas el trabajo con cinco letras que pertenecen a esos tópicos potencialmente conflictivos ${ }^{8}$.

Enlapresentecomunicación pretendoexponerlas distintasoperacionesinterpretativas y prácticas de apropiación puestas en juego en la instancia de la recepción por parte de 26 de estos tangueros, operaciones y prácticas que nos permitirán comprender cómo la poesía del tango es capaz de seguir interpelando a muchos argentinos, casi un siglo más tarde, y más allá de las evidentes distancias socioculturales.

6 Aunque sí podían formar parte de sus "preferidos" por sus características musicales -especialmente instrumentales- antes que por sus letras. Esa separación de capas de sentido entre música y letra fue dominante en la escucha orientada al baile, pero no necesariamente se sostenía en la escucha hogareña, donde el sentido atribuido a la letra podía cobrar mucho más protagonismo (Montes, 2014).

7 Claudio Díaz (2013) señala con justeza que en la instancia de la recepción los agentes sociales realizan opciones en un marco de posibles y que esas opciones son ya una forma de producción de sentido. Optando entre géneros musicales y entre distintas tradiciones dentro de ese campo, por ejemplo, los receptores se instalan como enunciadores, diciéndole al resto a qué géneros musicales y tradiciones desean verse asociados. Las opciones de unos tópicos por sobre otros son, también en este caso, prácticas de apropiación que instalan un enunciador que se asocia a esos tópicos y a la valoración social que se hace de ellos.

8 Concretamente: Yo tengo una novia (Marcó, 1936), Se va la vida (Carnelli, 1929), Baldosa floja (Gilardoni, 1957), Contramarca (Brancatti, 1930) y Cuando me entrés a fallar (Flores, 1940). 
Para facilitar su comprensión, la exposición vendrá ordenada por tópicos. Introduciremos al lector en aquellos temas del tango que son potencialmente disonantes junto con las canciones abordadas durante las entrevistas. A la par, iremos describiendo las operaciones y prácticas puestas en marcha por los entrevistados en cada uno de esos casos.

\section{MADRESSANTAS,CONSEJOSCÍNICOSYVIOLENCIA DE GÉNERO}

\subsection{SANTA MADRECITA}

La madre es, sin lugar a dudas, uno de los tópicos más característicos del tango. En todos los casos, la madre es esa figura femenina que se contrapone a la mujer amante, carente de moral (la "milonguita", la "percanta", etc.) como su antítesis. La madre que todo lo perdona, completamente deserotizada, es la encarnación del amor incondicional y del sacrificio ilimitado (Moreau, 2000; Ulla, 1982). La madre parece vivir únicamente para esperarlo a él, al hijo varón, regresar al hogar arrepentido. Él puede irse, olvidarla, abandonarla vieja y enferma, pero ella ha de esperarlo con el perdón eterno, pues esa es su virtud.

En todos los casos, funciona como la figura femenina antitética a la perversa "milonguita", la mujer joven que se fue al centro, que aspiró a otra vida, que no se resignó a vivir en el barrio para ser lavandera pobre como su madre. La mujer buena, la mujer virtuosa, la mujer ejemplar, es la que profesa el amor incondicional y desinteresado por el varón. Esa cualidad, en la poesía del tango, la encarna siempre la mujer madre y muy pocas veces la mujer amante. La figura de la madre funciona como ejemplo, pero también como la vara que mide la desviación de la mujer amoral.

Por este motivo se incluyó entre las actividades la letra del vals tangueado Yo tengo una novia (Marcó, 1936), frecuentemente escuchado en las milongas cordobesas en la versión de la orquesta de Ángel D'Agostino:

Yo tengo una novia

eterna y sincera.

Si son de sus labios,

no hay besos más grandes!

Si tardo en la cita,

sonriente me espera...

besando mi frente

porque llegue tarde! 
Yo tengo una novia, no hay otra más buena, más noble y más pura. Jamás va a engañarme!

Por ella gustoso

daría mi vida

porque ella no miente porque ella es mi madre!...

Ante esta letra, y en otros casos también, los/as milongueros/as tomaron distancia en relación al enunciador. La mayoría ni se sentía identificado con el enunciador, ni conseguía empatizar con él. Un frecuente "no me gusta" señalaba un distanciamiento, produciendo un rechazo que era de índole personal antes que interpretativo. Quiero decir con esto que ninguno negó que se tratase de un tópico característico del tango, ni fallaron en reconocer su objeto, sino que lo que negaron fue su capacidad de interpelarlos personalmente.

Ahora bien, este distanciamiento en relación al enunciador y a la relación con su madre se presentó principalmente bajo dos formas distintas. La primera, una operación de crítica, que algunas veces tomó la forma de cuestionamiento serio y en otras ocasiones tomó la forma de burla:

V_33: No, esto no... Con este no me siento... [risas]

Entrevistadora: ¿Con este no?

V_33: No, no.

Entrevistadora: ¿En ningún momento?

V_33: En ningún momento. No, no soy de esos... No, no. Tengo, como todo porteño, una cosa así con la madre, pero tampoco la pavada. ${ }^{9}$

V_49: Ohhh chiquito... ¡Marche un terapeuta para el señor! [...] Pero no podés... Menos mal que no se le dio por la cuestión de sexo... No, no, no. ¡Nooo! Aparte, ya de infantil me parece tonto.

La crítica se dirige a la relación del personaje con la madre antes que a las virtudes femeninas que ella encarna, las cuales parecieron no entrar en contradicción con lo que los entrevistados consideraban que debía ser el amor de madre. Existe aquí una continuidad entre los valores morales en los que se sustenta la idea de maternidad en las

9 Los nombres de los entrevistados han sido reemplazados por un código donde la letra M oV corresponden al sexo del entrevistado, mientras el número que le sigue corresponde a su edad al momento de la realización de la entrevista. En todos los casos la puntuación en la transcripción pretende conservar, lo mejor posible, los rasgos propios de la oralidad. 
letras de los tangos, y entre los de los actuales milongueros cordobeses, una suerte de memoria común (Lotman, 1996) que parecía bien activada por el texto.

Aquello que juzgaron erróneo, era el poner en plano de comparación a la amante con la madre, colocando a esta canción en la categoría de "tangos que no les gustan". La madre ya no debería ser, desde las condiciones de enunciabilidad actuales, la legítima vara con la que deban vérselas las novias.

El segundo tipo de operación de distanciamiento observada consiste en la justificación del personaje, o de su comportamiento, a través de su contextualización y alejamiento en el tiempo, pero sin que por ello dejase de ser un comportamiento reprochable del cual buscaban distanciarse. Se pretende comprenderlo, justificarlo, a veces valorarlo como elemento folklórico, pero manteniendo la no identificación con ese enunciador. Como consecuencia, conseguían distanciarse del enunciador sin que el tango les resultase agresivo o perturbador, ni exigiera de ellos una declaración de rechazo:

M_29: Este me parece como que son de tangos muy viejos, ¿no? De temáticas viejas. Y no me llega.

Entrevistadora: No te llega, ¿no?

M_29: No, es como que estamos en otro contexto, en otra cosa.

M_59: [risas] "Porque es mi madre". Sí, tangos viejos.

Entrevistadora: Tangos viejos. ¿Te identificás con esta letra, te llega...?

M_59: No, no... Me parece que es el tango de antes, en donde la madre era esa novia... la eterna novia [... .] Tangos viejos que a mí no me dicen nada. Contemporáneamente... Está bueno que quede en la historia, porque así pensaba el hombre de antes.

En ambos casos el distanciamiento que producen en relación al enunciador y a sus valores, constituye una forma -negativa- de apropiación. Esto quiere decir que utilizan estas formas de distanciamiento para construir una imagen valorada de sí mismos, moralmente acorde a las condiciones actuales de enunciación.

\subsection{EL CINISMO TANGUERO}

Muchos son los tangos en los que el enunciador se presta para dar un consejo o transmitir un saber ganado, generalmente, con la experiencia. Este es el caso de Se va la vida (Carnelli, 1929). En este caso, el enunciador le aconseja a una muchacha que no pretenda ser virtuosa, que renuncie al amor desinteresado, y que intente acomodarse económicamente con un hombre adinerado. 
Se va la vida...

se va y no vuelve.

Escuchá este consejo;

si un bacán te promete acomodar ${ }^{10}$,

entrá derecho viejo ${ }^{11}$.

Se va, pebeta ${ }^{12}$, quién la detiene

si ni Dios la sujeta,

lo mejor es gozarla y largar

las penas a rodar.

Yo quiero, muchacha,

que al fin mostrés la hilacha ${ }^{13}$

y al misio recuerdo ${ }^{14}$

le des un golpe de hacha.

Decí, pa qué queres

Ilorar un amor

y morir, tal vez,

de desesperanza.

No rogués la flor

de un sueño infeliz

porque, a lo mejor,

la suerte te alcanza

si te decidís.

Se va la vida...

se va yno vuelve,

escuchá este consejo;

si un bacán te promete acomodar,

entrá derecho viejo.

Pasan los días, pasan los años,

es fugaz la alegría,

10 Bacan es un término lunfardo que proviene del dialecto genovés $y$, en el caso argentino, designa al hombre adinerado. Para este y los siguientes casos la traducción de las locuciones lunfardas es nuestra. Para mayores precisiones, u otros usos de las mismas locuciones, se recomienda consultar en: http://www. todotango.com/comunidad/lunfardo/

11 Entrar derecho viejo: Animarse, no dudar en hacerlo, actuar sin preámbulos.

12 Pebeta: mujer joven.

13 Mostrar la hilacha, significa enseñar las bajezas, los defectos o las miserias.

14 Misio, mishio, miscio: Mísero, pobre. 
no pensés en dolor ni en virtud,

viví tu juventud.

Entre las operaciones interpretativas más recurrentes al trabajar con esta letra, la separación y ponderación de diferentes capas de sentido fue la más frecuente. El concepto de capas de sentido es deudor de la metáfora del hojaldre que usara Paolo Fabbri (2000) para dar cuenta del espesor del lenguaje. Lo que aquí entendemos por capas de sentido son unas organizaciones de sentido que se reconocen como coexistentes dentro de un mismo paquete significante, pero con una relativa autonomía.

Esta separación consistía en distinguir dos consejos no necesariamente ligados entre sí: por una parte el fin, el consejo de disfrutar la vida y de no dejar pasar el tiempo, y por el otro el medio para conseguirlo, acomodarse con un "bacan". Separar así estos dos mensajes les permitía estar de acuerdo con uno y no con el otro. En algunos casos la ponderación de una capa por sobre la otra era más explícita y hasta voluntaria -una forma de apropiación-. Ellos/as interpretaban la existencia de estos dos consejos como igualmente pertinentes pero decidían, por preferencia personal y no porque alguna norma interpretativa así lo exigiera, ponderar una por sobre la otra.

M_41:A míme encanta. Me encanta este tango, me encanta bailarlo a este tango. Incluso me encanta como letra. Jamás estaría, por ejemplo, de acuerdo con esto, "Se va la vida, se va y no vuelve. Escuchá este consejo. Si un bacán te promete acomodar, entrá derecho viejo". A ver, no sería el consejo que yo le voy a dar a mi hija. ¡Ni en pedo! „Ni por casualidad! Entonces, [es] que en el tango pasa esto. Y bueno, me pasaba con las otras letras. Que puedo estar más de acuerdo con algunos aspectos y no con esta parte. Me puedo enganchar con esto de "se va la vida, se va y no vuelve". Entonces, esto de, "pasan los días, pasan los años, es fugaz la alegría, no pensés en dolor ni en virtud. Viví tu juventud". Eso me parece bárbaro. [...]

Pero en la mayoría de los casos la ponderación de una capa por sobre otra apareció menos claramente voluntaria. Una capa de sentido atrajo más la atención de los entrevistados anulando a la otra, dejándola en segundo plano como si se tratase de algo irrelevante y hasta a veces subvirtiéndolo. La separación de capas de sentido, en este caso, se daba como una operación interpretativa. Luego, en función de cuál capa de sentido ponderaron, su posicionamiento en torno la letra fue completamente diferente. Los que ponderaron el objetivo del consejo (la mayoría) manifestaron que es un tango que les agrada, mientras que los que ponderaron los medios aconsejados (acomodarse con un hombre adinerado, renunciar a la virtud) se mostraron o bien críticos (distanciándose en consecuencia) o bien contextualizándolo como algo de otro tiempo (y distanciándose también). 
V_22: Me gusta la letra como lo... bueno, también... como muestra un consejo de que uno tiene que vivir la vida... Digamos, no buscar lo material, sino también de ser feliz. Entonces, me gusta como muestra el consejo que se está dando...

M_31: Sí, para qué llorar en realidad, por algo que no... Eso me transmite. Es muy cierto, pero son cosas que vos vas aprendiendo con el correr de los años y con las experiencias que vas teniendo, me parece. Son cosas muy reales, es verdad. Se va la vida, se va y no vuelve. Para qué perder tiempo con algo que sabés que no va a dar sus frutos, ¿me entendés? Viví la juventud. Es hoy, mañana no se sabe si estamos acá. Está buena la letra.

M_57: No, tampoco. [...] Porque yo soy de la idea que... "si un bacán te promete acomodarte, entrá derecho viejo", no. Juégatela y viví tu amor y listo. Si vos no necesitás [de] ningún bacán...

Entrevistadora: Contigo pan y cebolla...

M_57: Claro. No necesitás un bacán para... También a mí nunca me ha mantenido nadie, entonces, como para qué quiero que alguien me mantenga. No quiero que alguien me mantenga, me mantengo yo sola.

Entrevistadora: Tal cual.

M_57: No sé en esa época cómo habrá sido, que las mujeres no trabajaban...

V_49: No, no es algo que me genere nada, nada, nada demasiado lindo. $O$ sea, lo primero "escuchá este consejo...." Ya eso, eso...

Entrevistadora: La actitud de...

V_49: De papá las sabe todas. "Si un bacán te promete, entrá derecho, viejo". O sea, acomódate a como dé lugar, ¿eh? "A un guaso que tiene guita15, loco, pegátele...". "Abrí las gambas16, total este guaso17 te va a llevar por el mundo...." No pensés en virtud. O sea... No, no, no. O sea, "mostrá la hilacha". No, no, no, para nada.

Idénticas operaciones de separación de capas de sentido y ponderación se hicieron presentes en otras letras como, por ejemplo, Baldosa floja (Gilardoni, 1957), una canción donde el enunciador se describe a sí mismo como una persona cuya vida está en la

15 Guita: dinero.

16 Gambas: piernas, especialmente usado para mencionar las de las mujeres.

17 Guaso, tipo: hombre. 
noche, en el baile, en la milonga, y que no es capaz de querer o de asentarse en una relación amorosa estable, priorizando la diversión y el baile por sobre el amor duradero.

Yo llevo el baile en la sangre

y cumplo con mi destino,

mi vida está en la milonga

y he de seguir por ese camino.

No soy constante en amores

por eso tan solo estoy,

mi carta me la he jugado

y si he perdido, pago y me voy.

Rebelde soy para el lazo

ni sus cadenas me echó el amor,

yo soy gorrión viajero

y el mundo entero fue mi ambición.

Igual que baldosa floja

salpico si alguien me pone el pie,

no sé... querer,

miamor... sefue,

yo iré... bailando

mientras las tabas

me den con que... ${ }^{18}$

Dependiendo de qué capa de sentido se ponderase, sobrevenían luego diferentes posicionamientos -apropiaciones- que iban desde la identificación plena con el personaje o la situación (cuando la interpretación ponderaba el "disfrutar la vida" o "amar el baile"), al distanciamiento (cuando lo que se ponderaba era el desapego afectivo). Este último se presentó nuevamente bajo las dos formas antes mencionadas: o bien una crítica abierta, o bien a través de una contextualización y relativa justificación.

Por otra parte, aunque menos frecuentemente, otra operación interpretativa apareció en este caso. Algunos/as milongueros/as optaron por suavizar los nodos de sentido más disonantes, aquellos que en otros generaban un rechazo pleno, relativizando la sinceridad del enunciador. Sirviéndose de la creencia de que a veces las personas no son honestas, o de que manifiestan lo contrario de lo que piensan, ellos pretendían ir más allá de lo dicho, esbozando una hipótesis sobre lo no dicho que volvía menos conflictivo

18 La letra original es más extensa, pero en esta investigación se utilizaron las letras en la versión efectivamente grabada y que escuchan los milongueros actualmente. Es muy frecuente que en las versiones grabadas las orquestas de tango eliminaran algunas estrofas para extender más las introducciones instrumentales. 
lo manifestado efectivamente. Concretamente, podían hipotetizar que el narrador de Baldosa floja en realidad no reivindicaba verdaderamente el desapego afectivo, sino que manifestaba eso porque había sido abandonado y sentía mucho dolor, y pretendía dar la imagen de que lo sobrellevaba airosamente. En otros casos podían simplemente suavizar lo dicho, aduciendo que la exageración es un recurso literario y que, en realidad, no había que tomarse esa parte tan en serio.

Por último, un último recurso surgido en este caso (y también en los que veremos a continuación) consistía en separar una capa de sentido relacionada con la forma antes que con el contenido de la letra. El gusto estético por el modo como está narrado se colocaba por encima de que lo se narraba, y del circunstancial acuerdo o desacuerdo con los valores que reivindica.

V_26: [comienza a cantarla mientras la lee]. Me gusta la melodía y la canción, pero la conozco a través de la melodía. [De] La letra, me quedo con esta frase, "Soy baldosa floja, salpico si alguien me pone el pie". Fantástica esa frase. Es como invento literario, me parece que está muy buena. La frase. Pero después, cuando vuelve al tema recurrente de que está solo y que lo dejaron, ahíya me cansa un poco.

Entrevistadora: Perfecto.

V_26: Pero ves, hago eso. Me quedo con las frases que me gustan. Me quedo con esa frase, está buena.

\subsection{VIOLENCIA DE GÉNERO}

Contramarca (Brancatti, 1930) es un tango correspondiente a tópico romántico en el que se narra una situación que, a la luz de lo decible de nuestro tiempo, sería cuestionable por reivindicar la violencia de género. En este tango, en un lenguaje gauchesco y con metáforas camperas, el enunciador relata la historia de desamor que lo lleva a rechazar a una mujer cuando ella toca nuevamente su puerta. Le reclama una traición, la trata como una propiedad (ahora de otro) y se jacta de la marca que él le hizo en la cara con su cuchillo."Contramarca”se le llama en la cultura gaucha a la marca que se le hace a un animal (del ganado especialmente) sobre una marca anterior, y que señala su pertenencia a un nuevo propietario.

En la larga siembra de mis años

medio indio $\mathrm{pa}^{\prime}$ lquerer,

siempre fui esquivando los zarpazos del amor,

pero en mi camino te cruzaste

yesa tarde, pa' dolor, 
con tus ojos criollos me chusiaste ${ }^{19}$.

$Y$ al yugo del cariño

me fui de yeno,

chasquiándome por güeno,

confiao y noble,

sintiéndome más pobre

que las arañas

dispués que por tus mañas

caí bajo tu pial... ${ }^{20}$

China ${ }^{21}$ cruel, ¿a qué has venido?

¿Qué buscás en este rancho?

Si pa' mí fuiste al olvido

y vive ya más ancho

migaucho corazón

y esa flor que mi cuchillo

te marcó bien merecida,

la yevarás, luciendo en el carriyo

pa'que nunca en la vida

olvidés tu traición.

En el viejo pértigo de mi alma

no te vengás a enredar.

Tenés contramarca. Sos ajena a este corral.

Con que andá apurándote las tabas ${ }^{22}$

pa'tu bien o pa'tu mal

y perdete en el potrero donde estabas.

Con un botón pa' muestra

tengo bastante

y soy de mucho aguante ${ }^{23}$

pa' caer de nuevo.

De juro, te lo ruego,

que al lao del tigre

19 Chuzar: herir, punzar.

20 Pial: Lazo que se utiliza para cazar o inmovilizar, arrojándoselo a la presa a las patas delanteras.

21 China: mujer.

22 Tabas: pies.

23 De mucho aguante: Valiente. 
es fácil que peligren

las zorras como vos.

Este tango replica bien el modelo del machismo bárbaro del que hablara Magalí Saikin, en el cual el dominio del hombre sobre la mujer se manifiesta de manera física y muchas veces brutal.

Ante este tango los entrevistados se mostraron menos inclinados a separar capas de sentido para omitir este elemento. Fueron menos los que, a la hora de traducir a una narración esos versos, optaron por no mencionar la agresión o la amenaza. Aquí este elemento tiene una presencia mucho más importante de la que tenía, por ejemplo, la cuestión del "acomodarse" en Se va la vida. Durante toda la canción el enunciador va creando la argumentación que pretende justificar la amenaza y la violencia que ejerce. Además la cuestión de la violencia de género aparece en la discursividad social actualmente muy tematizada en este país. Probablemente por esto es que omitir ese elemento les resultaba más difícil. Es importante destacar esto, porque si bien la recepción es una instancia activa de producción de sentido, dicha producción se realiza condicionada por múltiples factores, entre los que destacan: Las competencias socialmente adquiridas de los distintos agentes sociales que intervienen, un determinado dispositivo de enunciación que posibilita determinadas lecturas y, todavía más, favorece más unas que otras (Díaz, 2013); y el contexto de recepción.

En este caso, la mayoría de los milongueros incluyeron en su narración la amenaza final o la agresión con el cuchillo (y muy frecuentemente ambas), y manifestaron algún tipo de toma de posición tendiente a distanciarse del enunciador. La crítica abierta fue frecuente, pero también apareció otra forma de crítica menos encendida y que es capaz de conducir a formas de apropiación positivas: el humor.

En sus diferentes formas, a través de la burla, el sarcasmo o la ironía, algunos milongueros se distanciaban del enunciador pero hallando en la canción un dispositivo que posibilita su fruición.

$V \_33: Y$ es rencoroso el muchacho [risas]. No, en serio. Gente que no sabe perder...

Entrevistadora: ¿Y [en] ésta, cómo narrarías la historia?

$V \_33: Y$, un tipo que se le fue la mano con el tema de la venganza... digamos [risas] Se sintió traicionado y... está claro que por ahí era como algo muy común. Lo que pasa es que había mucho cuchillo en esa época...

Entrevistadora: Había demasiado cuchillo. 
V_33: Demasiado cuchillo. Aparte de buena calidad. Porque después salió el tramontina, viste, y no podés hacer mucho daño con los tramontina. [risas] ${ }^{24}$

El mismo tipo de operaciones interpretativas revistadas hasta aquí se observaron a la hora de trabajar con Cuando me entrés a fallar (Flores, 1940), un tango en el que un enunciador varón describe su enamoramiento, pero reconoce que se considera un hombre viejo, vulnerable, y por eso tiene miedo de que ella lo pueda abandonar. Todo este relato viene a justificar la amenaza de muerte con la que se corona la letra.

He rodao como bolita de pebete arrabalero y estoy fulero ${ }^{25}$ y cachuso ${ }^{26}$ por los golpes, ¿qué querés?

Cuantas veces con un cuatro a un envido dije ¡Quiero!... y otra vez me fui a baraja y tenía treinta y tres $^{27}$.

Te conocí cuando entraba a fallarme la carpeta ${ }^{28}$, me ganaste con bondades poco a poco el corazón. El hombre como el caballo, cuando ha llegado a la meta afloja el tren de carrera y se hace manso y sobón ${ }^{29}$.

Vos sos buena, no te alcanza ni el más mínimo reproche y sos para mí una amiga desinteresada y leal, una estrella en lo triste de mi noche, una máscara de risa en mi pobre carnaval... Vos me torciste la vida, te pusiste en mi camino para alumbrarme con risas, con amory con placer. Yentré a quererte, por esa ley del destino sin darme cuenta que estaba ya viejo para querer...

¿Viejo?...Porque tengo miedo que me sobrés ${ }^{30}$ en malicia.

¿Viejo?...Porque desconfío que me querés amurar ${ }^{31}$.

24 Tramontina designa a una marca de cubiertos, pero que en Argentina se hizo muy conocida por un tipo de cuchillo serrucho, de bajo costo, muy utilizado en la vida cotidiana.

25 Fulero: Feo, desagradable.

26 Cachuso: Deslucido, demejorado, deteriorado.

27 Hace referencia a un juego de naipes argentino/uruguayo: El Truco. Allí se apuesta al "envido" cuando un jugador lo "canta" (decirlo, pedirlo) y el rival acepta el "envite" (la invitación), diciendo "quiero". Gana el jugador que suma más puntos con los naipes, siendo 4 el naipe más bajo (una derrota casi segura) y 33 el puntaje máximo posible (una victoria casi segura).

29 Sobón: adepto a las caricias.

30 Sobrar: ser más diestro o inteligente.

31 Amurar: abandonar. 
Porque me estoy dando cuenta que fue mi vida ficticia

y porque tengo otro modo de ver y filosofar.

Sin embargo, todavía, si se me cuadra y me apuran

puedo mostrarle a cualquiera que sé hacerme respetar.

Te quiero como a mi madre, pero me sobra bravura

pa'hacerte saltar pa'arriba "Cuando me entrés a fallar".

En el plano interpretativo, algunos ponderaron la cuestión del miedo de entregarse al amor, de volverse vulnerable, y omitieron la amenaza como si se tratase de un dato prescindible, especialmente entre los entrevistados de edad avanzada. Cuando se les preguntó sobre ese elemento, manifestaron que era algo negativo, pero que no era lo verdaderamente importante de la letra ${ }^{32}$. Muchos dijeron sentirse identificados con el enunciador en sus miedos. Lo importante parecía estar allí, en esa confesión desgarrada de la persona que se siente cansada y teme profundamente sufrir el abandono.

Otros/as, en cambio, se quedaban con la forma, disfrutando de las metáforas de la cultura popular sin necesidad de identificarse con el enunciador. Otros, en cambio, incluyeron la amenaza como parte esencial de la letra y eso los obligó a tomar posición -en la instancia de la apropiación- y a distanciarse del enunciador.

V_26: "viejo porque tengo miedo que me sobres en malicia, viejo porque desconfío que me querés amurar..." Está buena la letra, porque tiene una estructura así poética... Y está como bien escrita. Tiene hasta frases y palabras y elementos que son propios de la cultura popular. Me parece que es una letra que está buena... para que quede en la historia [se ríe]. Que quede ahí un tiempo, ¿no? Porque, esta parte que si no me queres te fajo ${ }^{33}$... [con gesto de desaprobación]

M_41: ¡Ah! Esta me encanta. [continua leyendo] jEs terrible lo que dice abajo! ¡Mi vida! [se ríe mientras niega con la cabeza] ;Es indefendible, mi vida! $Y$ eso que, qué sé yo [... j $Y$ encima tiene partes que a mí me gustan! Encima! ¡Eso es doloroso! Reconocerme en esto es doloroso. [se ríe a carcajadas]

Entrevistadora: ¿Cuáles son las partes que te gustan?

32 En todos los casos se buscaba que fueron ellos mismos los que seleccionaran, en primera instancia, lo que consideraban digno de destacarse del poema para observar las omisiones y las ponderaciones que realizaban. Pero luego el entrevistador introducía a través de preguntas los temas potencialmente disonantes si éstos no habían emergido de manera espontánea para observar sus posicionamientos (un entrevistado puede no mencionar la cuestión de la violencia bien porque está de acuerdo con ella, o porque no considera que sea algo importante, o porque no lo entendió de esa manera).

33 Fajar: ejercer violencia, golpear. 
M_41:Por ejemplo, "Cuántas veces con un cuatro o un envido dije, 'Quiero".' Me encanta. Tiene que ver con lo que yo te decía recién. iMe encanta que me lo definan así! Me fascina. Y lo que sigue. "Y otra vez me fui a baraja y tenía", "Te conocí cuando entraba a fallarme la carpeta" [...] iMe parece maravillosa la forma de definir! Me encanta. Lo relaciona siempre con la timba ${ }^{34}$. En general, la timba y el caballo. iMe encanta! "El hombre como el caballo cuando ha ganado la meta, afloja el tren de carrera y se hace manso y sobón". iEstá bárbaro! ¿Entendés? ¡Eso es genial! Pero bueno, después, mi vida, cuando le ponés acá, "te quiero más que a mi madre... pero me sobra bravura... [risas] ¡Pa hacerte saltar p'arriba!'... ¡Es terrible!

M_25: Si, está bueno, jestá muy bueno! Y está muy bueno el hecho de buscar muchas... iMetáforas!

Entrevistadora: Y eso del caballo...

M_25: "El hombre como caballo cuando ha llegado a la meta, afloja el tren de carrera y se hace manso y sobón". "se sonríe con satisfacción mientras la sigue leyendo y asiente] Sí, es tal cual. Este está hermoso.

La crítica abierta y directa fue muy frecuente, pero aquí también apareció esa otra forma de la crítica a través de la burla y la ironía. Tal vez, lo más interesante de este posicionamiento sea el hecho de que les permite disfrutar del tango al mismo tiempo que se distancian del enunciador, a diferencia de aquellos que toman una posición de crítica abierta y frontal, que lo toman más seriamente, y se ven obligados a rechazarlo:

\section{V_33: Este es buenísimo.}

Entrevistadora: Yo sabía que te iba a gustar esta.

V_33: Uh, ¿después me la pasás a esta letra? Bueno, la puedo buscar en internet.

Entrevistadora: llevátela.

V_33: Muy buena, muy buena. Esta me encantó. [risas]

Entrevistadora:Te gusta...

V_33:Seee.

Entrevistadora: ¿Temática? ¿Si tuvieras que ponerle un tema?

V_33: un tipo que está muy asustado. Que se siente que es la última oportunidad del amor. Entonces, amenaza, trata de mantenerla a través... de la coerción, digamos. [lo dice mientras se ríe y se burla del enunciador]

34 Timba: juegos de azar, término especialmente usado en los que involucran apuestas. 
A diferencia de la crítica directa el humor, a través de la burla y del sarcasmo, permite no tomar como cierta la construcción del personaje o sus acciones tal como el enunciador lo demanda. El lector no colabora, por decirlo en términos equianos (Eco, 1987), como se pretende de él, no acepta la valoración propuesta para el personaje (en este último caso la de varón peligroso) y la subvierte. Así, ese enunciador que por sobre todas las cosas exige que lo tomen en serio, a fuerza de amenaza, se convierte en el chiste, en la muesca triste de un hombre demasiado vulnerable como para reconocerlo.

\section{CONCLUSIONES}

Como hemos intentado exponer hasta aquí los/as milongueros/as reconocen que la lírica del tango involucra diferentes tópicos y, aunque las letras de tangos románticos son su opción preferencial, no desconocen la existencia otros tangos como los que exaltan el amor a la madre, los que reivindican el cinismo, la noche o la violencia de género.

Ante estas otras narrativas ponen en marcha distintas operaciones interpretativas y prácticas de apropiación que permiten atenuar una parte importante de aquello potencialmente disonante en relación a sus creencias y sus moralidades. Es el caso, por ejemplo, de la separación y ponderación de capas de sentido no conflictivas por sobre las otras, acción que pueden realizar en el momento mismo de la interpretación, anulando así los componentes potencialmente conflictivos. También la contextualización y justificación, así como la elaboración de hipótesis sobre lo no dicho que atenúan o incluso subvierten lo manifestado explícitamente, son otras operaciones que también contribuyen a hacer menos conflictivas estas canciones. $Y$ cuando en el plano interpretativo las operaciones puestas en marcha no consiguen atemperar los conflictos, resta la instancia de la apropiación, donde siempre pueden privilegiar una capa de sentido menos conflictiva o, incluso, aspectos formales o estilísticos y el goce estético derivado de éstos, por sobre el componente narrativo.

Así, del universo discursivo del tango que era potencialmente disonante, en la práctica, a ellos les queda un universo mucho más reducido con el que lidiar, haciendo que lo conflictivo con sus moralidades quede reducido a una pequeña proporción. Estas opciones y sus combinaciones se ven claramente reflejadas en la figura 1.

Ahora bien, resulta importante destacar, finalmente, que estas operaciones y prácticas no se encuentran ligadas una a una con un tópico tanguero específico. Tampoco el tipo de operación puesta en marcha aparecía ligada a una disposición personal (no había unos entrevistados que evidenciaban más una operación que otra). Por dar un ejemplo: una misma persona a la hora de interpretar Baldosa floja hacía una lectura que activaba las dos capas de sentido principales y se distanciaba parcialmente del enunciador emprendiendo una crítica abierta hacia él, mientras que a la hora de interpretar Se va la 
vida ponderaba una sola capa de sentido, omitiendo por completo ese elemento más contradictorio con sus sistemas de valores, lo cual le permitía apropiarse de la canción y valorarla positivamente. Paralelamente, a la hora de interpretar Cuando me entrés a fallar, optaba por distanciarse pero contextualizando y justificando al enunciador.

Tampoco se observó, hasta donde este estudio pudo llegar, tendencias diferentes entre varones y mujeres, ni entre milongueros de diferentes edades.

Apenas se esbozó una tendencia entre los adultos de edad avanzada, en el caso de Cuando me entrés a fallar. Allí podemos avanzar la hipótesis de que la construcción de un enunciador de edad avanzada y la descripción de su temor al abandono habría detonado un fuerte sentimiento de empatía e identificación, consiguiendo que en varios casos esto cobrara mayor peso -en el plano interpretativo- que la cuestión de la violencia de género (haciendo de las posibilidades de apropiación abiertas por la coincidencia en el componente generacional entre enunciador e intérpretes, un condicionante de las operaciones interpretativas). Sin embargo, por tratarse de un grupo pequeño de casos es imposible inferir tendencias generales, aunque sí permiten vislumbrar una vía de indagación para futuras investigaciones.

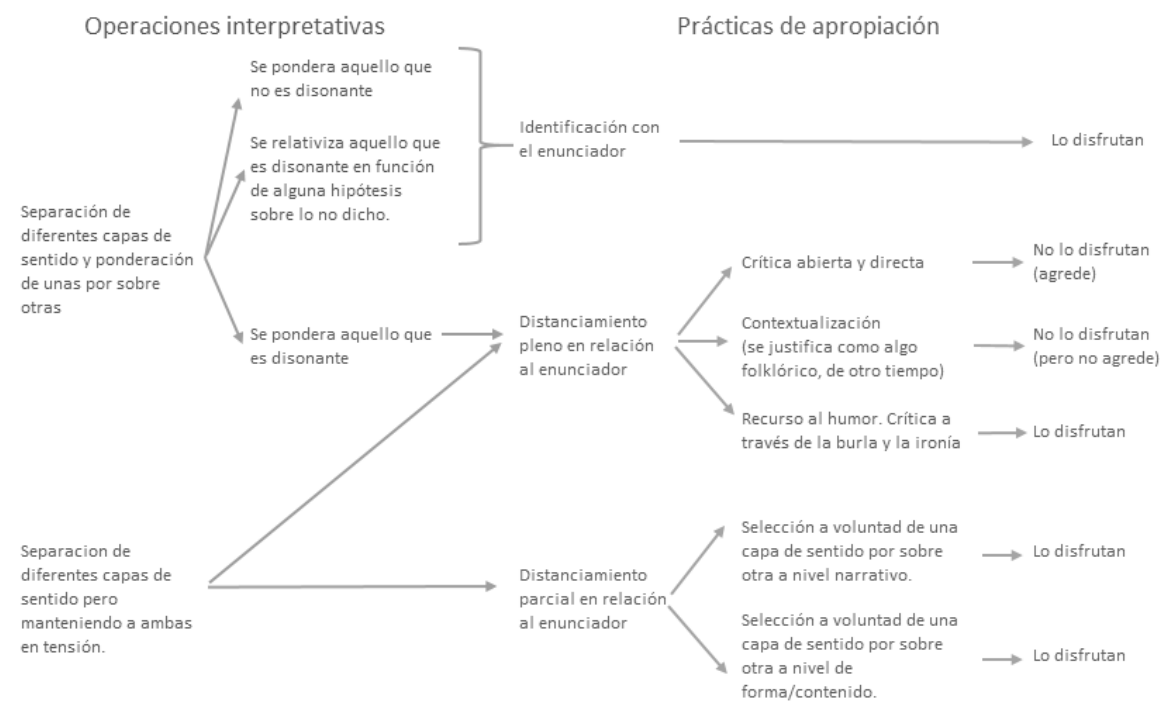

Figura 1. Relaciones entre operaciones interpretativas y prácticas de apropiación.

En su conjunto, estas operaciones interpretativas y las prácticas de apropiación que les siguen, permiten comprender cómo una lírica nacida en los albores del siglo XX es capaz de interpelar a este nuevo público casi un siglo más tarde. Lo hace no sólo porque la topicalización y la selección que ellos realizan al momento de apropiarse del tango les permite priorizar aquellos tangos menos conflictivos sino, también, porque cuando se 
los enfrenta a estos casos que deberían ser conflictivos, las operaciones interpretativas puestas en marcha en muchos casos o bien invisibilizan esos elementos conflictivos, o bien los suavizan. Vale decir, no en todos los casos se activa esa incoherencia moral, haciendo que los casos conflictivos se conviertan en una proporción pequeña del universo discursivo del tango.

Y en los casos en los que el conflicto aparece efectivamente a ellos les queda, todavía, la posibilidad de realizar una apropiación parcial. Las normas que regulan la apropiación de la lírica tanguera, en esta comunidad, habilitan esta apropiación parcial e, incluso, una apropiación que va a contramano de lo que en términos equianos exigiría la intentio operis de esos poemas.

\section{REFERENCIAS BIBLIOGRÁFICAS}

ARCHETTI, E. (2003). Masculinidades. Fútbol, Tango y Polo en Argentina. Buenos Aires: Antropofagia.

DE CERTEAU, M. (2000). La invención de lo cotidiano I. Artes de hacer. México: Universidad Iberoamericana.

DÍAZ, C. (2013) "Recepción y apropiación de músicas populares: Dispositivos de enunciación, lugares sociales e identidades". El oído pensante 1(2). Disponible en línea: $h t t p: / / p p c t . c a i c y t$. gov.ar/index.php/oidopensante [Última consulta 12/12/2013].

ECO, U. (1987). Lector in fabula. Barcelona: Lumen.

(1992). Los límites de la interpretación. Barcelona: Lumen.

FABBRI, P. (2000). El giro semiótico. Barcelona: Gedisa.

FLICK, U. (2007). Introducción a la investigación cualitativa. Madrid: Morata.

GLASSER, B. \& STRAUSS, A. (1967). The Discovery of Grounded Theory: Strategies for Qualitative Research. Nueva York: Aldine.

LISKA, M. (2012). Vanguardia "plebeya". El baile del tango en el paradigma transcultural (19902010). Tesis de Doctorado en Ciencias Sociales (inédita). Facultad de Ciencias Sociales, Universidad Nacional de Buenos Aires.

LOTMAN, I. (1996). La semiosfera III. Semiótica de las artes y de la cultura. Madrid: Frónesis.

MERTON, R.; FISKE, M. \& KENDALL, P. (1998). “Propósitos y criterios de la entrevista focalizada”. Empiria (UNED) 1, 215-230.

MONTES, M. a de los Á. (2014). "Operaciones interpretativas y prácticas de apropiación de signos con materialidad múltiple en la recepción del tango". AdVersuS, año XI.27, 32-57. Disponible en línea: http://www.adversus.org/indice/nro-27/articulos/XI2703.pdf [Última consulta: 18/04/2012] 


\section{MARÍA DE LOS ÁNGELES MONTES}

(2015a). "El lugar del poder en la perspectiva decerteana". Lo popular en la estructura de la experiencia contemporánea: emergencias, capturas y resistencias, M. E. Boito (ed.), 23-49. Buenos Aires: El Colectivo Editorial.

(2015b). “Entrevista productiva. Una adaptación de entrevista focalizada orientada a abordar los procesos interpretativos". RELMIS (Ciudad de Buenos Aires: CIES - Estudios Sociológicos Editora), año 5.9, 35-49. Disponible en línea: $h$ ttp://relmis.com.ar/ojs/index. php/relmis/article/view/138/115 [Última consulta 16/05/15].

(2016a). "Algunas claves para entender la vigencia de la poesía romántica del tango argentino desde un estudio en recepción". Signo y Pensamiento (Pontificia Universidad Javeriana, Bogotá, Colombia), № XXXV.68, 118-132. Disponible en línea: http://revistas. javeriana.edu.co/index.php/signoypensamiento/article/view/17207/13715 [Última consulta 04/12/2016].

(2016b).“Dimequétango quieres y te diréquién eres”. La Tramadela Comunicación (Rosario, Universidad Nacional de Rosario), VOL 20. Disponible en línea: http://www.latrama.fcpolit. unr.edu.ar/index.php/trama/article/view/567/422 [Última consulta: 04/12/2016]

MOREAU, P. (2000). La poesía del tango. Fueron años de cercos y glicinas... Córdoba: Comunicarte Editorial.

PAOLUCCI, C. (2013). Strutturalismo e interpretazione. Ambizioni per una semiótica "minore". Milano: Bompiani [Kindle versión].

SAIKIN, M. (2004). Tango y género. Stuttgart: Abrazos Book.

ULLA, N. (1982). Tango, rebelión y nostalgia. Buenos Aires: Centro Editor de América Latina.

VILA, P. (1996). "Identidades narrativas y música. Una primera propuesta para entender sus relaciones". TRANS Revista Transcultural de Música 2. Disponible en línea: http://www. sibetrans.com/trans/articulo/288/identidades-narrativas-y-musica-una-primera-propuestapara-entender-sus-relaciones [Última consulta 16/08/2011]. 
EL TANGO ARGENTINO EN RECEPCIÓN: INTERPRETACIÓN Y APROPIACIÓN DE UNA LÍRICA QUE INVOLUCRA MADRES SANTAS, CONSEJOS CÍNICOS Y VIOLENCIA DE GÉNERO

\section{CORPUS DE CANCIONES UTILIZADAS DURANTE LAS ENTREVISTAS}

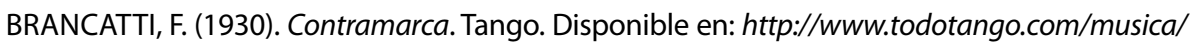
tema/36/Contramarca/

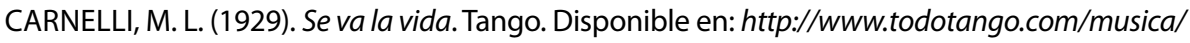
tema/1983/Se-va-la-vidal

FLORES, C. (1940). Cuando me entrés a fallar. Tango. Disponible en: http://www.todotango. com/musica/tema/199/Cuando-me-entres-a-fallar/

GILARDONI, D. (1957). Baldosa Floja. Milonga. Disponible en: http://www.todotango.com/ musica/tema/1392/Baldosa-floja/

MARCÓ, H. (1936). Yo tengo una novia. Vals. Disponible en: http://www.todotango.com/musica/ tema/754/Yo-tengo-una-novia/

Recibido el 15 de enero de 2016.

Aceptado el 25 de noviembre de 2016. 
